\title{
A Novel Thick-Film Electrical Conductivity Sensor Suitable for Liquid and Soil Conductivity Measurements
}

\author{
Marios Sophocleous* and John K. Atkinson \\ Faculty of Engineering \& the Environment, University of Southampton, UK
}

\begin{abstract}
Results are reported from an initial evaluation of a novel conductivity sensor that could be incorporated onto a multi-element thick film (screen printed) sensor array designed for soil and water analysis. The new sensor exhibits a repeatable cell constant over a wide range of conductivities and is currently performing very well in an investigation of soil structural properties where its output is being correlated with soil water content in a study of different soil porosities.
\end{abstract}

Keywords: Thick Film Sensors, Electrical Conductivity, Cell Constant

\section{Introduction}

Increasing interest in optimal environmental management, site-specific crop management (SSCM) and climate impact on soil behaviour have all resulted in a rising demand for in-situ soil sensing among many environmentalists and soil scientists [1-3]. Floodplain ecosystems are dependent on the specific hydrological regime but the mechanisms controlling species composition of the hydrological regime and related temperature and nutrient levels have not yet been fully understood [4]. SSCM, also called precision agriculture, evaluates variability in soil properties (e.g., pH, temperature, organic matter, water content and soil nutrient levels) to optimize inputs such as fertilizers and herbicides for an optimised agricultural growth [3]. Specific soil parameters and their critical limits are considered to reflect the impact of the climate on soil behaviour [5] and require monitoring to identify changes in soil quality which will provide the basis of understanding some of nature's unknown mechanisms for various agro-ecological zones at district, national and global levels [6]. Low cost, miniaturised electrochemical and physical sensors with modest electronic instrumentation demands that can be buried in the soil allow for an online high density sensor network providing vital data information for the understanding of climate impact on soil behaviour and furthermore on the ecosystem of an area.

Measuring soil conductivity can provide vital information on soil quality as well as distinguishing between different types of soil (e.g. clay, gravel, sand, limestone, coal and several combinations of them) [7-8]. Conductivity readings combined with porosity measurements can give information on the stability of the ground [9-10] which can be extremely important in applications such as monitoring of train rail supporting structures. Electrical conductivity of soil solutions can also be a reliable indicator of 
ionic concentration and the practice of measuring soil apparent electrical conductivity to evaluate soil salinity has been spreading continuously since the 1970s [11-12]. A significant incentive for the determination of soil solution electrical conductivity from apparent electrical conductivity measurements has developed from the possibility of simultaneous measurements of apparent electrical conductivity and soil volumetric water content [13-14]. The water content and soil solution electrical conductivity are the major factors affecting the apparent electrical conductivity. However, this relationship depends on additional soil and environmental attributes, which limits the predictability of general, theoretical relationships and often necessitates performing laborious, sitespecific calibrations. A general model that relies on easily attainable soil parameters has not yet been proposed [10].

Although conductivity probes are available commercially, their cost including the instrumentation required to take readings renders them unfeasible for high density sensor networks [15-17]. Thick film conductivity sensors are of low cost, rugged, miniature and robust design and have the ability to be integrated onto a single substrate with other thick film sensors to form a 'lab-on-chip' sensing array. In a previous design for a thick film environmental sensor array [18], planar conductivity cell electrodes were simultaneously printed along with other electrochemical sensor electrodes on the same device such that the conductivity electrodes were produced with no additional cost other than the insignificantly small microgram amount of electrode material used. In addition, due to the sensor design the required electronic interface circuits can be of low complexity providing the opportunity for a higher density sensor network in the investigation area [19].

\section{Background Theory}

Although electrical conductivity $(\sigma)$ is widely accepted as a simple and well understood principle, if the material of interest is non-homogeneous or non-isotropic it becomes more complicated and more difficult to measure. Electrical conductivity is defined as the reciprocal of resistivity $(\rho)$.

Assuming the material to be homogeneous and isotropic then $\rho$ becomes a scalar defined by equation (1):

$$
\rho=(\mathrm{V} / \mathrm{I}) \cdot(\mathrm{A} / \mathrm{L})
$$

where $\mathrm{V}$ is the potential difference $(\mathrm{V}), \mathrm{I}$ is the current $(\mathrm{A}), \mathrm{A}$ is the cross sectional area through which the current flows $\left(\mathrm{m}^{2}\right), \mathrm{L}$ is the distance over which the potential difference is applied $(\mathrm{m})$ and $\rho$ is the resistivity $(\mathrm{Ohm} \mathrm{m})$. Conductivity is defined as the reciprocal of resistivity and is measured in Siemens per meter $(\mathrm{S} / \mathrm{m})$ although sometimes it is more conveniently expressed as $\mathrm{mS} / \mathrm{cm}$. Therefore, from equation (1) conductivity can be calculated as:

$$
\sigma=(\mathrm{I} / \mathrm{V}) \cdot(\mathrm{L} / \mathrm{A})
$$

where $\mathrm{V}$ is the measured voltage $(\mathrm{V}), \mathrm{I}$ is the drive current $(\mathrm{A})$ and the term $\mathrm{L} / \mathrm{A}$ is the cell constant $\left(\mathrm{m}^{-1}\right)$ [20]. The specific sensor described here is based on the 4 electrodes method of conductivity measurement using an alternating square wave current source as the excitation signal. The conventional 4 electrodes method is very simple and more details on the theory can be found elsewhere [7]. 
In this 4 electrode method the outer electrodes, which are in contact with the sample measurand, are the current carrying electrode pair and the inner electrodes are the voltage $(\Delta \mathrm{V})$ measuring electrode pair. Assuming that the current passing between the two outer electrodes is equal to the current passing through the inner ones, the electric field developed between the voltage electrodes depends on the electrical impedance of the sample. Using Ohm's law, the impedance of the measurand can be calculated and if a constant current source (I) is used then that impedance is equivalent to the impedance of the measured sample. If the cell constant (L/A) is also known the conductivity of the solution can be calculated using equation (3). However due to fringing of the electric field between the electrodes, these two currents are not the same and hence the cell constant becomes a function of the fringing. The fringing in turn is a function of the conductivity of the measurand, giving rise to non-linearity in the measurement of conductivity. There are however, several advantages to using the 4 electrodes method including the minimisation of polarisation effects as well as a longer electrode lifetime and a wider measuring range. The use of an alternating current source also minimises any polarisation effect and in particular, the use of low frequencies minimises any errors that might arise due to the effective capacitance of the measurand. The commonly used frequency range is from about $100 \mathrm{~Hz}$ to several $\mathrm{kHz}$, because at lower frequencies electrode polarization interferes with the readings and at higher frequencies apparent conductivity is no longer constant at the dc value, but increases with frequency (a phenomenon termed dispersion) [10].

\section{Sensor Fabrication \& Geometry}

Planar arrangements for conductivity sensors, such as those used in some previous studies [18, 19] have several disadvantages, especially for soil. The most important drawback is that for soil sensing it is often desirable to monitor over a relatively large volume of soil (as compared to liquids) to compensate for any lack of homogeneity in the sample. This requirement generally dictates a much larger spacing of the electrodes, which can further exacerbate the problems of fringing as a result of increased electrical path length. One way around this is to also increase the effective cross-sectional area of the measured sample by increasing the surface area of the electrodes thereby maintaining the cell constant; however this simple expedient can still prove sensitive to electrode alignment issues. An alternative strategy has been adopted here that exploits ratiometric symmetry in the electrode arrangement to overcome some of these issues.

An initial design for a previously described multi-element sensor array [18] utilised a simple 4 electrode planar conductivity cell where the electrodes were made of a high purity platinum ink (Heraeus RP 10001-145B) printed on a ceramic substrate (96\% alumina, Coors Tech). However due to significant issues with variable fringing at different analyte conductivities the cell geometry was changed in a subsequent design to that of the 3 dimensional model depicted in figure 1, using a supporting structure that was produced on a 3D printer to space two substrates, each carrying three electrodes, facing one another across the volume of analyte to be measured. 

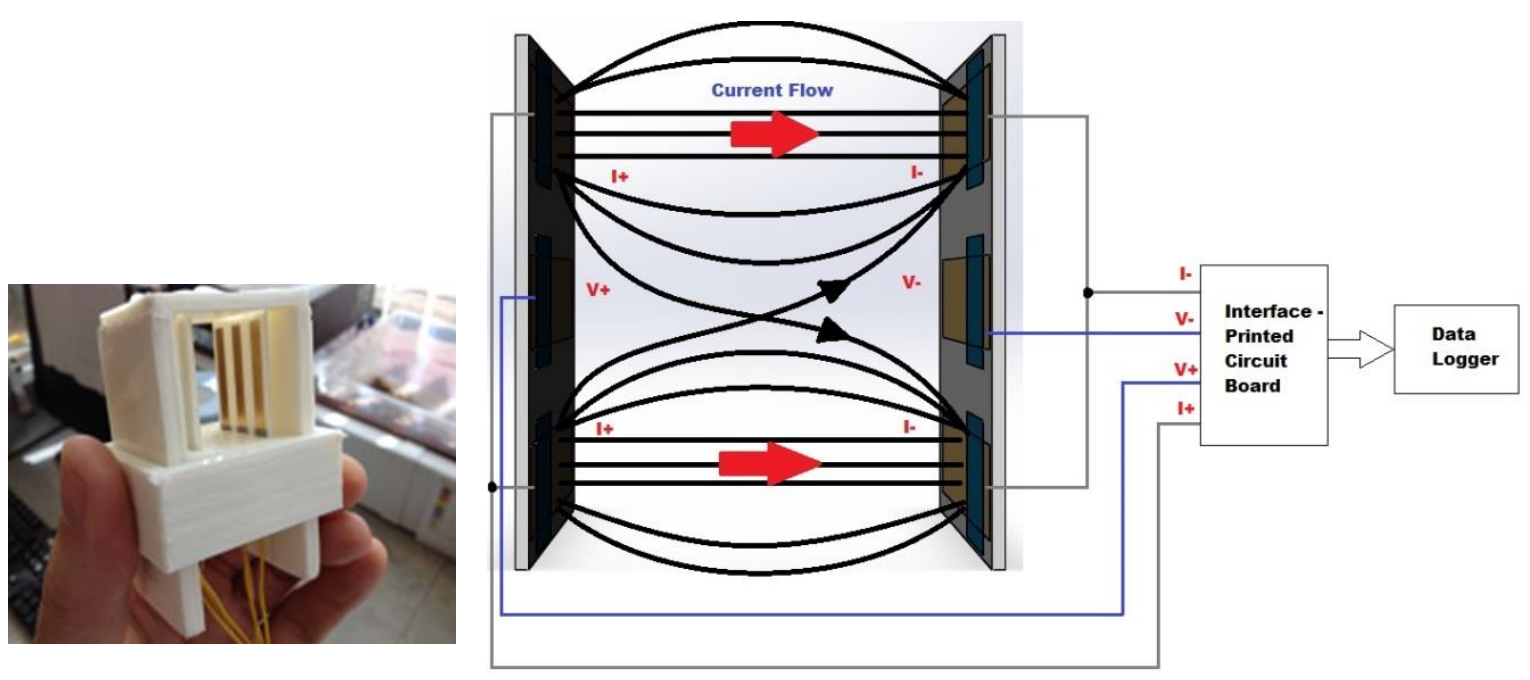

Figure 1: Conductivity cell electrode configuration and geometry

The design of the sensor is such that the drive current is applied across the two outer sets of electrodes, while the resulting potential across the cell is measured by the inner electrode on each substrate. This approach also facilitated the printing of one half of the conductivity cell onto the back of an existing sensor array [18] with an identical electrode pattern printed on a second substrate mounted opposite and facing the first. By using this geometry, any fringing will be minimised because of the positioning of the voltage measuring electrodes in between the two oppositely driven outer electrode pairs, additionally any rotation or tilting of the two substrates relative to one another will be cancelled out.

In order to decrease the printing cost of the new design the use of gold electrodes, in addition to platinum, was investigated to check for any difference in performance. The electrodes for the new sensor design were screen printed onto $50 \mathrm{~mm}$ $\times 25 \mathrm{~mm}, 0.625 \mathrm{~mm}$ thick, $96 \%$ alumina substrates (Coorstech) using stainless steel screens with a mesh count of 250 lines per inch, $15 \mu \mathrm{m}$ emulsion thickness and a $45^{\circ}$ mesh. The screen designs for each layer were produced using AUTOCAD and the screens were manufactured by MCI Cambridge for the Aurel C880 Printer. The first layer deposited was the gold or platinum conductor with rectangular screen mesh openings with dimensions of $4.5 \mathrm{~mm} \times 45 \mathrm{~mm}$. A waterproofing layer with a rectangular shape of $6.5 \mathrm{~mm} \times 14 \mathrm{~mm}$ was deposited on top of that; leaving an exposed area of $26 \mathrm{~mm} \times 4.5 \mathrm{~mm}$ of the underlying gold or platinum to comprise the individual electrodes. The distance between each electrode on the same substrate is approximately $5 \mathrm{~mm}$. A part of the conductor, approximately $5 \mathrm{~mm} \times 4.5 \mathrm{~mm}$, was left exposed at one end for soldering connecting wires. The gold electrodes were printed using 8844 ink (Electro Science) while the platinum electrodes were printed using 5545 ink (Electro Science), on top of which a glass dielectric insulator 4905-C (Electro Science) was deposited to isolate the electrode connection pads from the measurement surface and to expose a precise surface area of the electrodes. All layers were held at room temperature for 10 minutes after printing to allow relaxation of surface stresses and then dried in a DEK 1209 infrared mini dryer at suitable temperatures. The layers were then cured in a 6 zone belt furnace (BTU VQ41). Drying and curing temperatures for each of the pastes comprising the subsequent layers are as detailed in Table 1. 


\begin{tabular}{lccccc}
\hline \multicolumn{1}{c}{ Layer } & Paste & $\begin{array}{c}\text { Drying } \\
\text { temperature }\left({ }^{\circ} \mathrm{C}\right)\end{array}$ & $\begin{array}{c}\text { Drying } \\
\text { time }(\mathrm{min})\end{array}$ & $\begin{array}{c}\text { Firing } \\
\text { temperature }\left({ }^{\circ} \mathrm{C}\right)\end{array}$ & $\begin{array}{c}\text { Firing } \\
\text { time } \\
(\mathrm{min})\end{array}$ \\
\hline Gold conductor & ESL-8844 & 125 & $10-15$ & 850 & $\sim 45$ \\
Platinum conductor & ESL-5545 & 125 & $10-15$ & 850 & $\sim 45$ \\
Dielectric insulator & ESL-4905-C & 125 & $10-15$ & 850 & $\sim 45$ \\
\hline
\end{tabular}

Table 1: Ink details, temperatures and times.

\section{Electronic Instrumentation}

The previously described thick film environmental sensor array is connected to a custom designed low power interface circuit implemented as a printed circuit board (PCB) of roughly similar dimensions to the sensor array itself, and shown in Figure 2. The interface circuits have been designed to produce dc voltages that correspond to the real-time measured values of $\mathrm{pH}$, dissolved oxygen, temperature and conductivity in such a way that they can be easily interfaced to a data logger or microprocessor analogue to digital converter. The PCB carries various circuit board jumpers and adjustable components to allow gain setting and offset compensation for easy calibration of the various sensors on the array to allow maximum flexibility of use.

The conductivity sensor interface circuit allows for drive signal frequencies in the range $100 \mathrm{~Hz}$ to $5 \mathrm{kHz}$ and also allows varying of the drive current amplitude up to a maximum of $10 \mathrm{~mA}$. Operating frequency, drive current level and gain sensitivity of the detecting amplifier are set by variable resistors on the PCB. The drive current signal used is a simple alternating polarity square wave and the resulting output square wave voltage from the sensor is converted to a single ended dc voltage proportional to conductivity by a multiplexed chopper rectifier circuit, as shown in Figure 2.
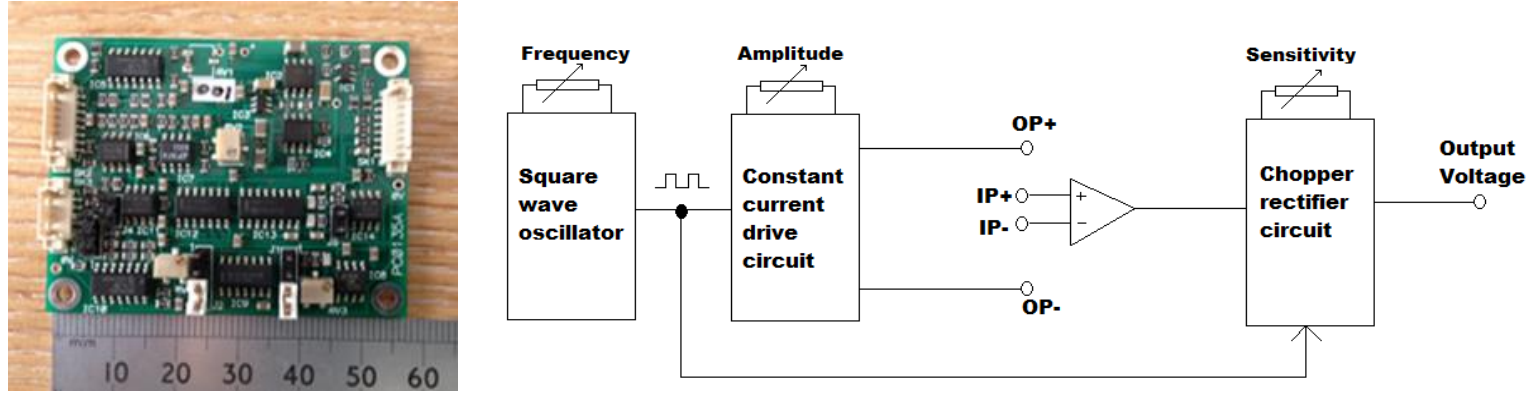

Figure 2: Sensor array interface circuit (left), Conductivity circuit block diagram. IP+ and IP- are connected to the voltage measuring electrodes of the cell while OP+ and $\mathrm{OP}$ - are connected to the current driving electrodes of the cell (right). 


\section{Methodology}

Experiments were performed to investigate the response of the sensor in various conductivity solutions and at various different drive frequencies and current levels, with two different electrode materials (gold and platinum) and with various distances between the two sets of electrodes. Test solution conductivities ranged from 0.2 to 4 $\mathrm{mS} / \mathrm{cm}$ with the different test solutions being prepared by dissolving potassium chloride (BDH 101984L AnalaR) in distilled water to a specific molarity for each conductivity $(0.2 \mathrm{mS} / \mathrm{cm}=1.4 \mathrm{mM}, 0.5 \mathrm{mS} / \mathrm{cm}=3.5 \mathrm{mM}, 1 \mathrm{mS} / \mathrm{cm}=7 \mathrm{mM}, 2 \mathrm{mS} / \mathrm{cm}=14 \mathrm{mM}$, $4 \mathrm{mS} / \mathrm{cm}=28 \mathrm{mM}$ ) The resulting conductivity was confirmed using a commercially obtained conductivity meter (HANNA Instruments HI 993310). The drive current levels in each of the test solutions were varied from 0.1 to $4 \mathrm{~mA}$. A frequency sweep over the range $(100 \mathrm{~Hz}$ to $5 \mathrm{kHz})$ was also carried out in each of the different conductivity test solutions. The investigating of the distance between the two facing sets of electrodes was a significant factor for the sensor and this was varied in stages between $15 \mathrm{~mm}$ to $40 \mathrm{~mm}$. The test solution temperature was also monitored and found to be approx. $25^{\circ} \mathrm{C}$ $\left( \pm 5^{\circ} \mathrm{C}\right)$ throughout all the tests.

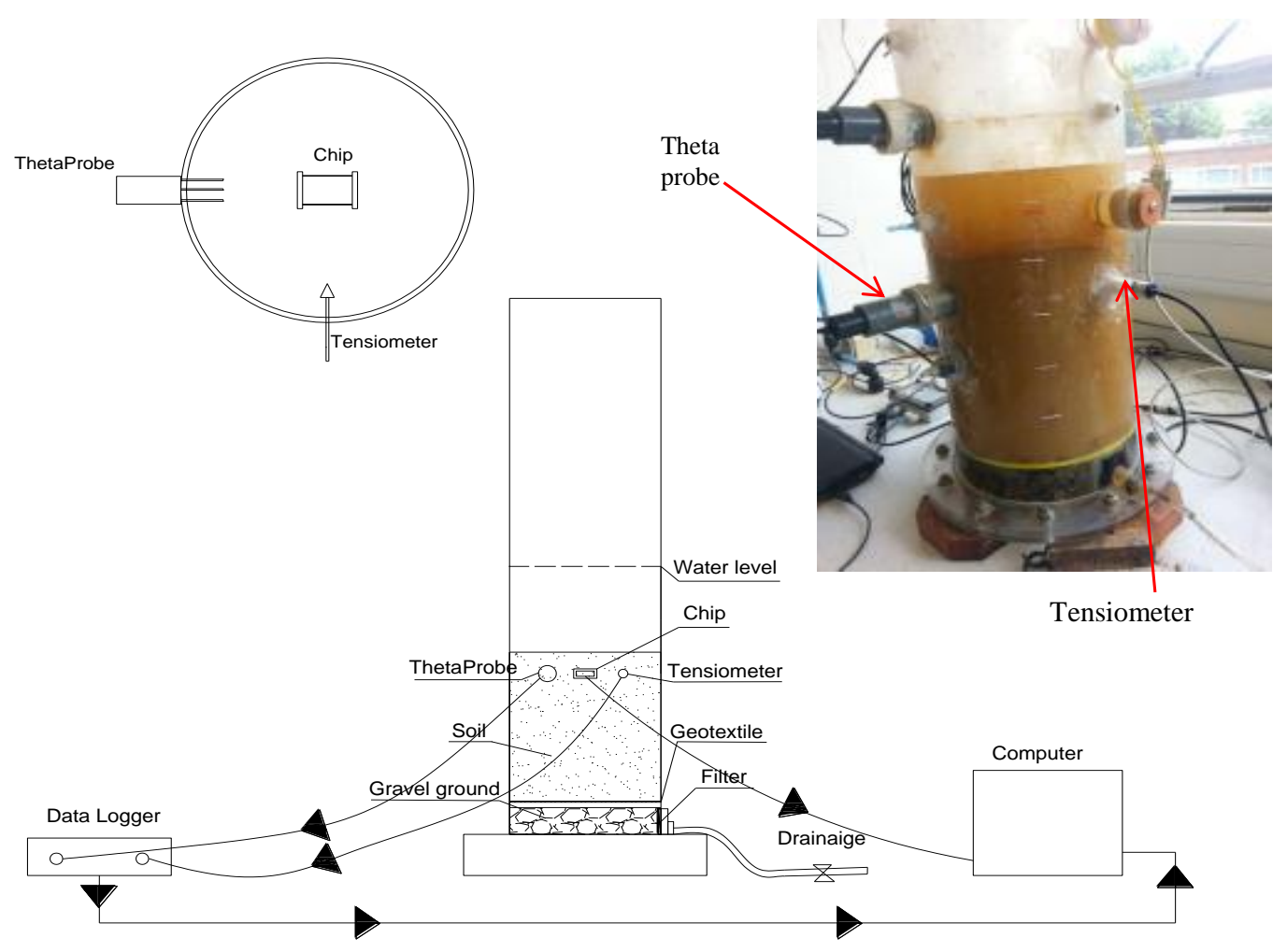

Figure 3: Photo (top right) plan (top left) and cross section (main) of soil column filled with builders sand and water showing sensors installed immediately below the surface of the sand. 
The results of tests using gold electrodes with $15 \mathrm{~mm}$ spacing between the two electrode substrates and drive current levels of 0.2 and $0.5 \mathrm{~mA}$ with $30 \mathrm{~mm}$ spacing were obtained using a custom designed data logger provided by Universidad de Valencia (detailed information on the data logger can be found elsewhere [21]). The rest of the readings were obtained using a commercial CR1000 data logger (Campbell Scientific). Further experiments were performed using a soil column containing commercially obtained builders' sand as shown in figure 3 . The conductivity sensor was buried in the sand at the same depth as a water content probe (ML2 Theta Probe, Soil Moisture Sensor, Delta-T) and readings from both sensors were logged as the water was allowed to drain out of the column.

\section{Results and Discussions}

In all the experiments, noise levels were seen as spikes with maximum values of lower than $\pm 9 \mathrm{mV}$ for any point in any experiment. Spikes of that amplitude are expected and arise due to other electrical equipment around the experimental setup as well as the mains.

Figure 4 shows the output voltage as a function of $1 \mathrm{~mA}$ current square wave at different drive frequencies resulting from placing the $15 \mathrm{~mm}$ spacing gold electrode conductivity sensor in different conductivity test solutions. With slopes of less than $9 \times 10^{-7} \mathrm{~V} / \mathrm{Hz}$ it can clearly be seen that there is no significant frequency effect on output voltage levels.
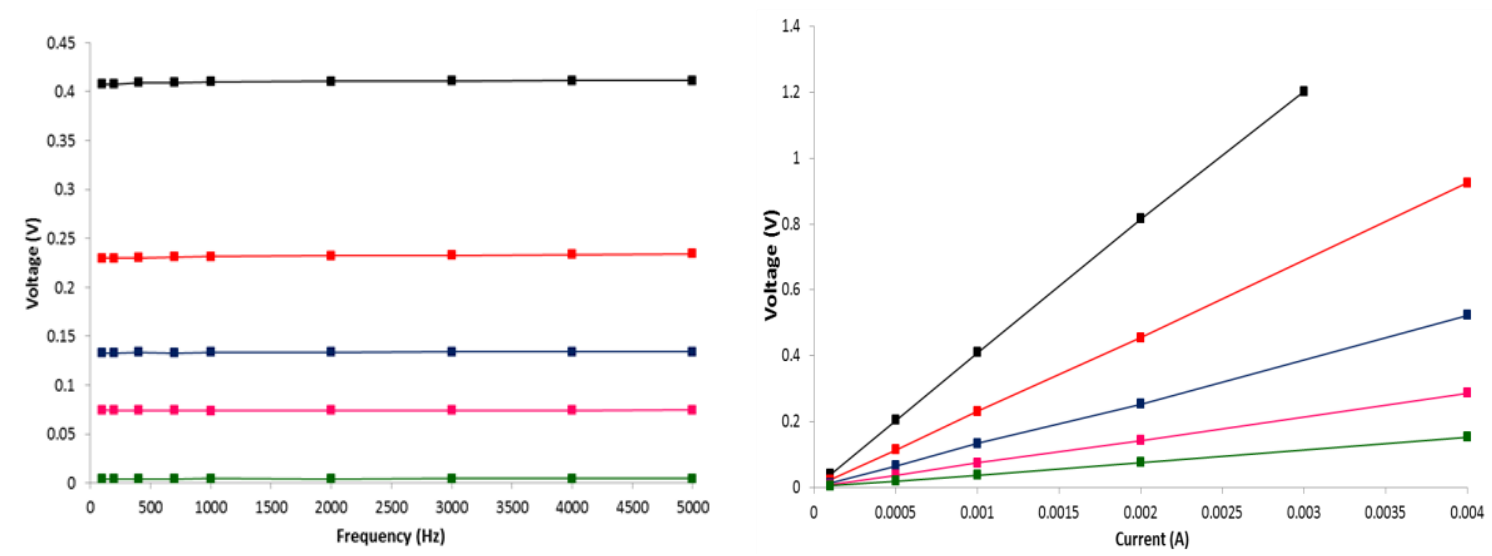

Figure 4: 15mm spaced gold electrode conductivity sensor output voltage levels as a function of $1 \mathrm{~mA}$ square wave current drive frequencies (left), and as a function of $1 \mathrm{kHz}$ drive current amplitude (right), in different conductivity test solutions. (green-4 mS/cm, pink-2 mS/cm, blue-1 $\mathrm{mS} / \mathrm{cm}$, red-0.5 mS/cm, black-0.2 mS/cm).

The sensor output voltage was found to be directly proportional to current and highly linear, exhibiting linearly increasing slopes in different conductivity test solutions. $\mathrm{R}^{2}$ values better than 0.9996 were obtained for linear fits to plots of voltage outputs for all combinations of electrode spacing and drive frequencies. 
Figure 5 shows plots of sensor output voltage in different conductivity solutions as a function of electrode spacing driven with $1 \mathrm{~mA}$ current square wave at a drive frequency of $1 \mathrm{kHz}$. The sensor output voltage was found to be linearly proportional to distance between the substrates with $\mathrm{R}^{2}$ values of better than 0.99 .

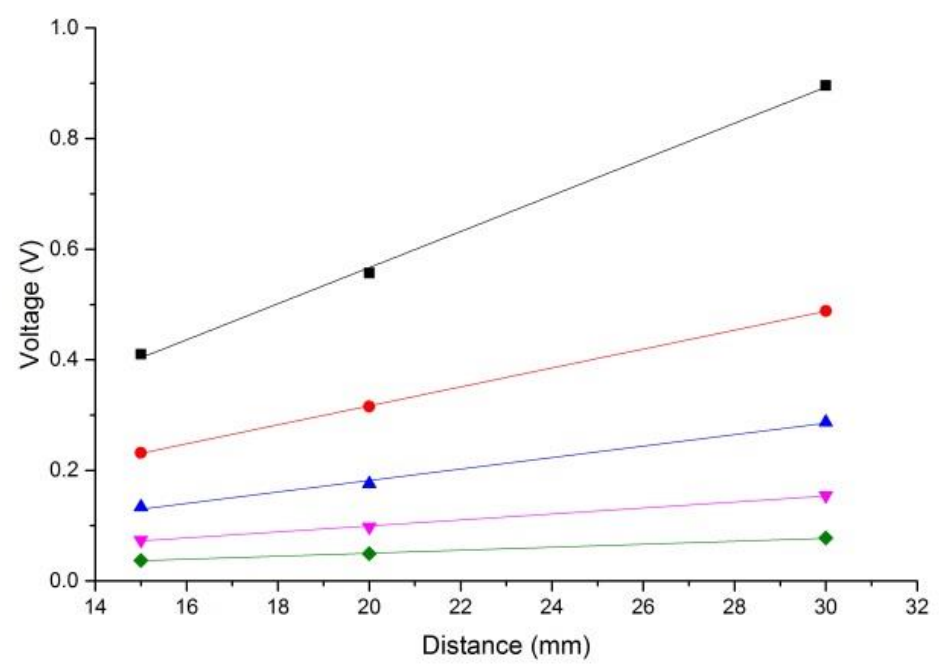

Figure 5: Sensor output voltage levels as a function of electrode spacing for $1 \mathrm{~mA}$ drive current square wave at $1 \mathrm{kHz}$ in different conductivity test solutions (green-4 $\mathrm{mS} / \mathrm{cm}$, pink-2 mS/cm, blue- $1 \mathrm{mS} / \mathrm{cm}$, red- $0.5 \mathrm{mS} / \mathrm{cm}$, black- $0.2 \mathrm{mS} / \mathrm{cm}$ )

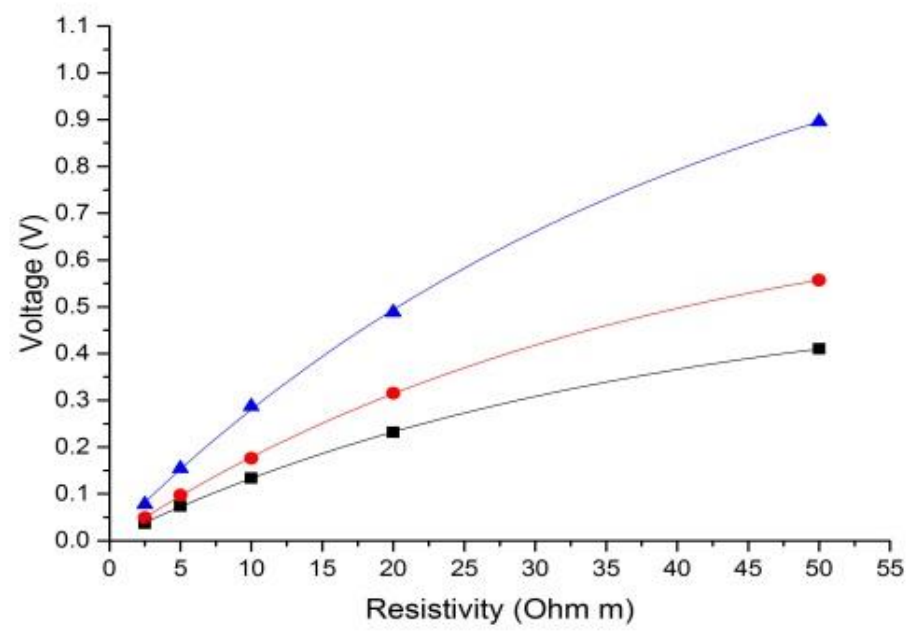

Figure 6: Sensor output voltage levels as a function of resistivity in different conductivity test solutions with $1 \mathrm{~mA}$ drive current square wave at $1 \mathrm{kHz}$ for different electrode spacing (black-15 mm, red-20 mm, blue-30 mm, purple-40 mm)

Figure 6 shows the sensor output voltages as a function of resistivity for different electrode spacings. It was observed that the relationship between voltage and resistivity is of the form:

$$
\mathrm{V}=\mathrm{A} * \exp (-\rho / \mathrm{B})+\mathrm{V}_{0}
$$


with R2 values better than 0.999 being obtained for both gold and platinum electrode types. Values of the constants A and B for different electrode spacing are as shown in Table 2 as well as expressions for the calculated cell constant for each distance. This non-linearity in the cell constant is due to fringing of the electric field in low conductivity solutions, below approximately $0.5 \mathrm{mS} / \mathrm{cm}$.

\begin{tabular}{|c|c|c|c|}
\hline \multicolumn{4}{|c|}{$\mathrm{dR} / \mathrm{d} \rho=-\left(\mathrm{A} /\left(I^{*} \mathrm{~B}\right)\right)^{*} \exp (-\rho / \mathrm{B})$} \\
\hline & $15 \mathrm{~mm}$ & $20 \mathrm{~mm}$ & $30 \mathrm{~mm}$ \\
\hline $\mathrm{A}$ & -0.54777 & -0.75185 & -1.26085 \\
\hline Cell Constant $\left(\mathrm{m}^{-1}\right)$ & 36.79427 & 37.08662 & 41.07856 \\
\hline $\mathrm{R}^{2}$ & $14.89 * \exp (-\rho / 36.79)$ & $20.27 * \exp (-\rho / 37.09)$ & $30.69 * \exp (-\rho / 41.08)$ \\
\hline
\end{tabular}

Table 2: Expressions for the cell constant in relation to spacing variations

\begin{tabular}{|l|r|r|r|}
\hline & \multicolumn{1}{|c|}{$15 \mathrm{~mm}$} & \multicolumn{1}{|c|}{$20 \mathrm{~mm}$} & $30 \mathrm{~mm}$ \\
\hline Cell Constant $\left(\mathrm{m}^{-1}\right)$ & 10.93 & 15 & 23.15 \\
\hline $\mathrm{R}^{2}$ & 0.99134 & 0.99543 & 0.98808 \\
\hline
\end{tabular}

Table 3: Cell constants in relation to spacing variations
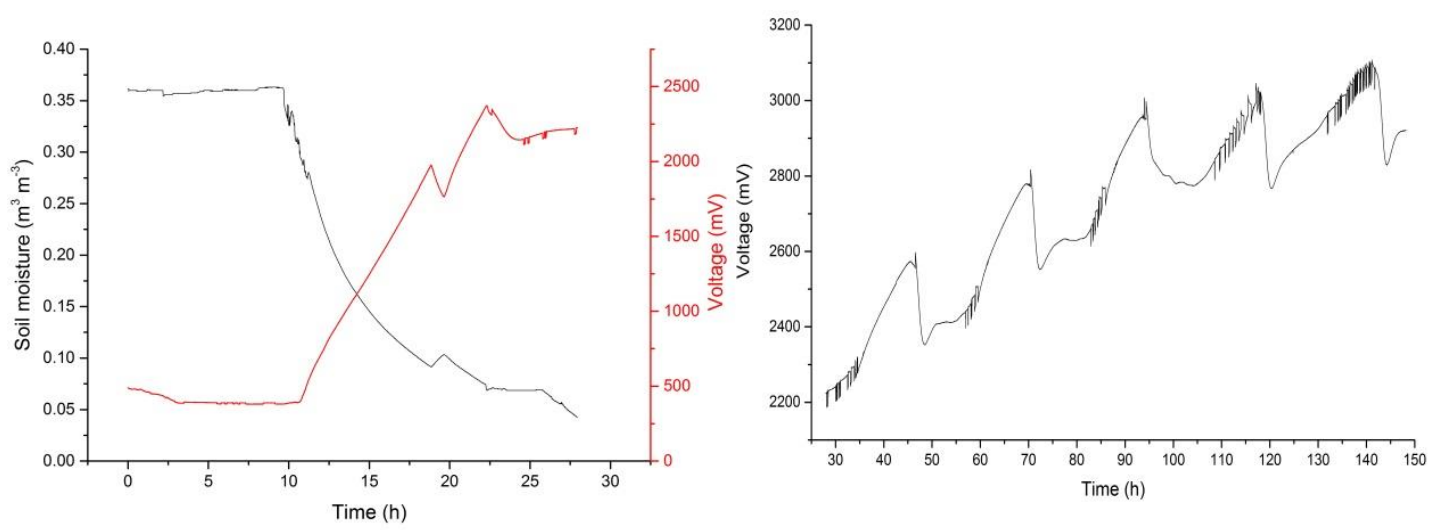

Figure 7: conductivity sensor output voltage levels compared with water content of the soil column as water is drained (left), showing fluctuation due to variation in day and night time temperatures and electrical pick up (noise spikes) from adjacent machinery (right).

Figure 7 shows a plot of sensor output voltage levels compared with water content for the $20 \mathrm{~mm}$ spacing gold electrode conductivity sensor operating with a $0.25 \mathrm{~mA}$ amplitude $1 \mathrm{kHz}$ square wave drive current while submerged in the soil column shown in Figure 3 and as the water is drained over time. The correlation between water content and conductivity can clearly be observed, with the decreasing water content causing the 
sensor output voltage to increase indicating an increase in soil resistivity. The artefacts at around 20 hours and 22 hours were due to a backing up of the draining water caused by temporary blockages in the flow of water out of the soil column.

Examination of the sensor output voltage from the 30 hour point onwards shows fluctuation on a 24 hour cycle due to day and night time temperature variations experienced by the soil column, which was subjected to strong sunlight through a laboratory window during the day. Electrical interference due to switching of electrical machinery in close proximity to the soil column can also be seen as a series of noise spikes during the day time portion of the plot. The latter are unlikely to be encountered in many of the application areas for these sensors but can be easily avoided with the use of electrical screening of the sensor connection wires, which for reasons of convenience was not done in this case. The variation of electrical conductivity due to temperature will however need to be compensated for in use and the included temperature sensor on the sensor array can easily be used for this purpose.

\section{Conclusions}

Initial results from testing of the sensor are very encouraging in that the device displays a linear response over a wide range of conductivities down to $0.5 \mathrm{mS} / \mathrm{cm}$ and is far more versatile when used in the measurement of soil conductivity than its planar constructed predecessor that was used in previous thick film sensor arrays [18]. In practice values of conductivity below $0.5 \mathrm{mS} / \mathrm{cm}$ are unlikely to be encountered in soil monitoring applications where the analyte ion content is generally relatively high. Versions of the novel conductivity sensor described here have been used to very good effect in a range of experiments concerned with the monitoring of soil structures, where the conductivity sensor output is being correlated with soil water content as measured by other commercially obtained instruments in an attempt to infer soil porosity by proxy.

\section{Acknowledgements}

The authors would like to thank the UK's Natural Environmental Research Council and Network Rail, UK for part funding this work.

\section{References}

[1] F. Kizito, C.S. Campbell, G.S. Campbell, D.R. Cobos, B.L. Teare, B. Carter, J.W. Hopmans, Frequency, electrical conductivity and temperature analysis of a low-cost capacitance soil moisture sensor, Journal of Hydrology (2008) 352, 367- 378.

[2] K.A. Sudduth, S.T. Drummond, N.R. Kitchen, Accuracy issues in electromagnetic induction sensing of soil electrical conductivity for precision agriculture, Computers and Electronics in Agriculture, 31 (2001) 239-264.

[3] J. Bouma, Land quality indicators of sustainable land management across scales, Agriculture, Ecosystems and Environment 88 (2002) 129-136.

[4] http://www.reading.ac.uk/geographyandenvironmentalscience/Research/ESS/ges-FUSE.aspx

[5] Hak-Jin Kim, Kenneth A. Sudduthb, John W. Hummelb, "Soil macronutrient sensing for precision agriculture”, J. Environ. Monit. vol. 11, 2009 p. 1810-1824. 
[6] M.A. Arshada, S. Martinb, "Identifying critical limits for soil quality indicators in agroecosystems", Agriculture, Ecosystems and Environment, vol. 88, 2002 p. 153-160.

[7] Misac N. Nabighian, "Electromagnetic methods in applied geophysics", Volume 1: Theory, United States of America: Society of explorationg geophysicists, 2006.

[8] Fritz Scholz, "Electroanalytical Methods: Guide to Experiments and Applications" United States of America: Springer, 2010.

[9] D. A. Robinson, * C. S. Campbell, J. W. Hopmans, B. K. Hornbuckle, S. B. Jones, R. Knight, F. Ogden, J. Selker, and O. Wendroth, "Soil Moisture Measurement for Ecological and Hydrological Watershed- Scale Observatories: A Review", Vadose Zone Journal, Vol. 7, No 1, 2008 pages 358-389.

[10] Shmulik P. Friedman, "Soil properties influencing apparent electrical conductivity: a review", Computers and Electronics in Agriculture, Vol. 46, Issue 1-3, 2005 pages 45-70.

[11] Rhoades, J. D., and R. D. Ingvalson. . Determining salinity in field soils with soil resistance measurements. Soil Sci. Soc. Amer. Proc. 1971 35:54-60.

[12] Rhoades, J.D., and J. van Schilfgaarde. . An electrical conductivity probe for determining soil salinity. Soil Sci. Soc. Am. J. 1976 40:647-650

[13] Topp, G. C., J. L. Annan, and A. P. Davis Electromagnetic determination of soil water content: Measurements in coaxial transmission lines, Water Resour. Res., 16, 1980 574-582.

[14] Robinson, D. A., S. B. Jones, J. M. Wraith, D. Or, and S. P. Friedman, A review of advances in dielectric and electrical conductivity measurement in soils using time domain reflectometry, Vadose Zone J., 2, 2003 444- 475.

[15] S. J. Zegelin, I. White, D. R. Jenkins, "Improved Field Probes for Soil Water Content and Electrical Conductivity Measurement Using Time Domain Reflectometry", Water Resources Research, Vol. 25, No. 11, 1989 Pages 2367-2376.

[16] M. A. Hilhorst, "A Pore Water Conductivity Sensor", Soil Science Society of America Journal, Vol. 64 No. 6, 2000 p. 1922-1925.

[17] Wei, Yaoguang, Wang, Jianqing, Li, Daoliang, Ding, Qisheng, "Design of Intelligent Conductivity Meter Based on MSP430F149", 3rd IFIP TC 12 International Conference of Computer and Computing Technologies in Agriculture, 2009.

[18] Gac, A., Atkinson, J.K., Zhang, Z. and Sion, R.P. A comparison of thick-film chemical sensor characteristics in laboratory and on-line industrial process applications, Measurement Science and Technology, 13, (2002) 2062-2073.

[19] Atkinson JK, Glanc M, Prakorbjanya M, Sophocleous M, Sion RP, Garcia-Breijo E. Thick film screen printed environmental and chemical sensor array reference electrodes suitable for subterranean and subaqueous deployments. Microelectronics International. 2013;30(2):92-8.

[20] Webster JG. Electrical Measurement, Signal Processing, and Displays: Taylor \& Francis; 2003.

[21] M. Glanc, M. Sophocleous, J.K. Atkinson, E. Garcia-Breijo, The effect on performance of fabrication parameter variations of thick-film screen printed silver/silver chloride potentiometric reference electrodes, Sensors and Actuators A 197 (2013) 1-8. 